\title{
CARBAMAZEPINE LOADED VESICULAR STRUCTURES FOR ENHANCED BRAIN TARGETING VIA INTRANASAL ROUTE: OPTIMIZATION, IN VITRO EVALUATION, AND IN VIVO STUDY
}

\author{
GHADA E. YASSIN ${ }^{1,2^{*}}$, REHAM I. AMER ${ }^{1,2}$, AHMED M. FAYEZ ${ }^{3}$
}

1Department of Pharmaceutics and Industrial Pharmacy, Faculty of Pharmacy, Al Azhar University, Cairo, Egypt, ${ }^{2}$ Department of Pharmaceutics, Faculty of Pharmacy, October University for Modern Sciences and Arts (MSA), Giza, Egypt, ${ }^{3}$ Department of Pharmacology, Faculty of Pharmacy, October University for Modern Sciences and Arts (MSA), Giza, Egypt

Email: gyassin@msa.eun.eg

Received: 06 Apr 2019, Revised and Accepted: 24 May 2019

\begin{abstract}
Objective: Carbamazepine (CBZ) is used as a first line in the treatment of grand mal and partial seizures, but it suffers from many side effects on different systems of the body. The objective of the present study was optimization of CBZ vesicular structures using $2^{3}$ multifactorial design for the
\end{abstract} most efficient targeting of CBZ to the brain via the intranasal route.

\begin{abstract}
Methods: The concentration of CBZ (10 and 20\%), type of vesicles (niosomes and spanlastics) and speed of rotation (200 and $300 \mathrm{rpm})$ were considered as the independent variables $X_{A}, X_{B}$ and $X_{C}$ respectively, while the dependent variables were particle size PS ( $\left.Y_{1}\right)$, polydispersity index PDI $\left(\mathrm{Y}_{2}\right)$, zeta potential ZP $\left(\mathrm{Y}_{3}\right)$ and entrapment efficiency EE $\left(\mathrm{Y}_{4}\right)$. The study of the effect of different formulation variables was carried out using Design-Expert ® software. CBZ-loaded spanlastics and noisome were prepared by the ethanol injection method and thin film hydration method, respectively. The optimized formulation was subjected to viscosity measurement, in vitro drug release and physical stability studies. In vivo evaluations in rats for the optimized formulation in comparison to oral CBZ suspension was carried out using behavioral assessment by elevated plus maze test, determination of endothelial nitric oxide synthase (e-NOS), reduced glutathione (GSH) and ELISA estimation of TNF $\alpha$.
\end{abstract}

Results: The selected optimized formulation $\left(\mathrm{F}_{0}\right)$ containing 20\% CBZ and spanlastic vesicular structure showed PS, PDI, ZP, and the EE \% of 350.09 $\mathrm{nm}, 0.830,16.124 \mathrm{mV}$ and $82.777 \%$, respectively. In vitro release study of $\mathrm{F}_{0}$ demonstrated the ability of the $\mathrm{F}_{0}$ to increase drug release in the range time from 10-60 min $(p<0.05)$ when compared with CBZ suspension. The viscosity of $\mathrm{F}_{0}$ was nearly uniform $(65 \mathrm{cps})$. The photomicrograph taken by the transmission electron microscopy (TEM) reveals the spherical shape of $\mathrm{F}_{0}$. Good physical stability for six months of storage at $25^{\circ} \mathrm{C}$ was found for $\mathrm{F}_{0}$. The optimized spanlastic formulation F0 showed a decrease in latency time in behavior assessment test using elevated plus Maze test, a decrease in serum eNOS and TNF- $\alpha$ and increase in GSH when compared with the oral CBZ suspension, in addition to the histopathological study that revealed the more CBZ uptake by the brain.

Conclusion: The optimized spanlastic formulation $\mathrm{F}_{0}$ achieved better results when compared with the oral CBZ suspension for targeting the CBZ spanlastics vesicular structure to the brain via the nasal route.

Keywords: Optimization, Carbamazepine, Spanlastics, Niosomes, Brain targeting, Elevated Plus Maze Test, Histopathology and Intranasal route

(c) 2019 The Authors. Published by Innovare Academic Sciences Pvt Ltd. This is an open access article under the CC BY license (http://creativecommons.org/licenses/by/4.0/) DOI: http://dx.doi.org/10.22159/ijap.2019v11i4.33474

\section{INTRODUCTION}

Epilepsy is a chronic neurological disorder characterized by the occurrence of two or more unprovoked seizures which are signs of excessive and synchronous neuronal discharge [1].

CBZ is an iminostilbene derivative; it has a similar structure to a tricyclic antidepressant. CBZ is used as a first line for the treatment of generalized tonic-clonic or partial seizure, and also it is used in psychiatric disorders, trigeminal neuralgia and schizophrenia [2]. CBZ has a specific mechanism to treat epilepsy by blocking sodium channel which leads to the delay of the recovery and decreases the firing's rate [3]. CBZ commonly exhibits the slow onset of action and systemic toxicity when administered via oral or intravenous (IV) routes due to the complex tight junctions between the endothelial cells of brain capillaries [4]. The intranasal route is the best choice to deliver CBZ directly to the brain, as this route exhibits several advantages as the good penetration and absorption of the small molecules, rapid delivery of therapeutic effect to blood and it can avoid metabolism by the first pass effect of the liver. The intranasal route delivers the drug to the brain through different pathways as the olfactory pathway, trigeminal nerve pathway or vascular pathway. Different dosage forms as Nasal drops, sprays, gel, solution, and suspension can be used via the intranasal route [4].

Nanotechnology played an important critical role in different biomedical applications not only in drug delivery. Nowadays it is utilized in targeted areas such as cancer targeting, brain targeting, and gene delivery. Nanotechnology is classified into nano-devices and nanomaterials which are classified into nanocrystalline and nanostructured which may be organic and inorganic particles [5]. The organic nanoparticles may contain polymeric nanosphere, nanocapsule, micelle, niosomes or liposomes. The inorganic nanoparticles are like dendrimers nanoparticle or carbon nanotube.

Niosomes are the novel systems for drug targeting, they consist of cholesterol which is responsible for the rigidity and stability of the carrier system, and nonionic surfactant which can carry either hydrophilic or hydrophobic drug [6-8]. They have many advantages as enhancement oral bioavailability, enhancement skin permeability and have better patient compliance. Niosomes or non-ionic surfactant vesicles (NSVs) show a high level of encapsulated drugs in the animals' brain which was reported in several types of research [9]. Increased brain uptake of doxorubicin reported when prepared as niosomes and when compared to the commercial doxorubicin [10].

Spanlastic vesicles (SV) are non-conventional types of niosomes composed of Span or Tween as edge activator is being widely used in drug delivery due to their deformability and elasticity $[11,12]$ The elastic property of SVs was previously reported in many researches and this elasticity helped the permeation of the drug through the different mucosal membranes as through the nasal.

The success of both niosomes and spanlastics to cross the bloodbrain barrier (BBB) and their ability to encapsulate both hydrophilic and lipophilic drugs, in addition to that nasal route offers a good penetration and absorption for lipophilic drugs especially to central nervous system (CNS) through the olfactory pathway, that help in fast and specific administration of the CBZ in emergency conditions, represent our aim to formulate and to 
optimize the best vesicular structure for brain targeting via intranasal route.

The aim of the present study was to optimize the CBZ nano-vesicular structures for rapid drug release, minimize the potential side effects and fasten the brain targeting via intranasal route and to study the cognitive enhancing mechanism of the CBZ by behavioral analysis using elevated plus maze test, histopathological examination and biochemical evaluation of the brain oxidative stress and inflammation.

\section{MATERIALS AND METHODS}

\section{Materials}

Carbamazepine (CBZ) was a gift from SEDICO pharmaceuticals, Giza (Egypt). Cholesterol was purchased from Bio Basic (Toronto, Canada). Span 60, was purchased from Oxford Lab Chem, Mumbai (India). Polyvinyl alcohol (PVA) was purchased from Sigma-Aldrich, St. Louis, USA. Pentylenetetrazol (PTZ) was purchased from Merck industrial company. All other chemicals and solvents were of pharmaceutical grade, from ADWIC Company (Qalyubia, Egypt).

\section{Methods \\ Preparation of spanlastics formulations}

CBZ-loaded spanlastics (F1, F4, F 6 and F7) were prepared by ethanol injection method as showed in table 1. CBZ and span 60 were dissolved in $10 \mathrm{ml}$ absolute ethanol and injected slowly in the preheated aqueous phase $\left(60^{\circ} \mathrm{C}\right)$ containing PVA and was stirred for $1 \mathrm{~h}$ on magnetic stirrer then, the formed dispersion was sonicated for 2 min. Eventually, the prepared formulations were left in the refrigerator until further investigation [13]. Experimental runs, independent variables and the measured dependent variables for the prepared formulations were given in table 1.

\section{Preparation of niosomes formulations}

Noisome formulations (F2, F3, F 5 and F8) as shown in table 1 were prepared by thin film hydration method. CBZ and span: cholesterol mixture (mole ratio 1:1) were dissolved in $10 \mathrm{ml}$ of methanol: chloroform mixture (volume ratio 1:2). The dried film was obtained by evaporation of the solvent using a rotatory evaporator at $60^{\circ} \mathrm{C}$ and under low pressure for $45 \mathrm{~min}$. This dried layer was then rehydrated using $5 \mathrm{ml}$ of phosphate buffer (pH 6.8) and rotated for 1 h. The vesicle suspension was sonicated for 2 min at $60^{\circ} \mathrm{C}[14]$.

Table 1: Experimental runs, independent variables and the measured dependent variables for the prepared formulations

\begin{tabular}{llllllll}
\hline $\begin{array}{l}\text { Formula } \\
\text { code }\end{array}$ & $\begin{array}{l}\text { Percentage of } \\
\text { CBZ (\%) }\left(\mathbf{X}_{\boldsymbol{A}}\right)\end{array}$ & $\begin{array}{l}\text { Type of } \\
\text { vesicles }\left(\mathbf{X}_{\mathbf{B}}\right)\end{array}$ & $\begin{array}{l}\text { Speed of rotation } \\
\mathbf{( r p m )}\left(\mathbf{X}_{\mathbf{C}}\right)\end{array}$ & $\begin{array}{l}\text { Particle size } \\
(\mathbf{n m})\left(\mathbf{Y}_{\mathbf{1}}\right)^{*}\end{array}$ & $\begin{array}{l}\text { Polydispersity } \\
\text { index }\left(\mathbf{Y}_{\mathbf{2}}\right)^{*}\end{array}$ & $\begin{array}{l}\text { Zeta } \\
\text { potential } \\
(\mathbf{m V})^{*}\left(\mathbf{Y}_{3}\right)\end{array}$ & $\begin{array}{l}\text { Entrapment } \\
\text { efficiency } \\
(\%)^{*}\left(\mathbf{Y}_{4}\right)\end{array}$ \\
\hline F1 & -1 & Spanlastics & -1 & $448 \pm 13.5$ & $0.95 \pm 0.04$ & $-9.9 \pm 0.4$ & $69.4 \pm 5.1$ \\
F2 & -1 & Niosomes & -1 & $2309.4 \pm 105.3$ & $0.65 \pm 0.07$ & $-14.6 \pm 0.5$ \\
F3 & 1 & Niosomes & -1 & $2990 \pm 117.2$ & $0.59 \pm 0.03$ & $-57.9 \pm 3.6$ & $96.9 \pm 4.3$ \\
F4 & 1 & Spanlastics & 1 & $413.6 \pm 21.5$ & $0.95 \pm 0.05$ & $-8.5 \pm 0.4$ & $91 \pm 4.6$ \\
F5 & -1 & Niosomes & 1 & $767.3 \pm 11.3$ & $0.74 \pm 0.04$ & $-60.6 \pm 5.2$ & $95.1 \pm 3.8$ \\
F6 & 1 & Spanlastics & -1 & $263.8 \pm 7.6$ & $0.85 \pm 0.05$ & $-10 \pm 0.6$ & $78 \pm 3.4$ \\
F7 & -1 & Spanlastics & 1 & $295 \pm 5.9$ & $0.99 \pm 0.05$ & $-4.6 \pm 0.1$ & $44 \pm 2.5$ \\
F8 & 1 & Niosomes & 1 & $1041.8 \pm 50.3$ & $0.80 \pm 0.04$ & $-58.9 \pm 3.4$ & $97.6 \pm 4.2$ \\
\hline
\end{tabular}

$\mathrm{X}_{\mathrm{A}}$ Percentage of CBZ (\%): Low level $(-1)=10 \%$, High level $(1)=20 \%$, $\mathrm{X}_{\mathrm{B}}$ Type of vesicles: Spanlastics or niosomes, $\mathrm{X}_{\mathrm{C}}$ Speed of rotation (rpm): Low level (-1):200 rpm, High level (1):300rpm, ${ }^{*}$ All results are the mean $\pm S D, n=3$

\section{Statistical optimization of the formulations}

A $2^{3}$ multifactorial factorial design was utilized to develop and optimize eight formulations and to investigate the relationship between independent variables and their responses. Design-Expert 10.0.1.0 ${ }^{\circledR}$ software (Stat-Ease Inc., Minneapolis, United States of America) was used to by changing the utilized concentrations of CBZ, type of vesicles and speed of rotation which were considered as the independent variables $\mathrm{X}_{\mathrm{A}}, \mathrm{X}_{\mathrm{B}}$, and $\mathrm{X}_{\mathrm{C}}$ respectively, as shown in table 1. On the other hand, dependent variables were PS ( $\left.Y_{1}\right)$, PDI $\left(\mathrm{Y}_{2}\right)$, ZP $\left(\mathrm{Y}_{3}\right)$ and EE $\left(\mathrm{Y}_{4}\right)$. Desirability values were measured to identify the optimum formula based on analyzing the response surface of the obtained data [13].

\section{Characterization of the prepared vesicles structures}

Determination of particle size (PS), zeta potential (ZP) and polydispersity index (PDI)

PS, size distribution (expressed in term of PDI) and ZP of the prepared vesicular systems were evaluated by dynamic light scattering (DLS) technique employing Zetasizer (Nano ZS-90, Malvern Inst., Worcestershire, UK). This technique analyzes the fluctuations in light scattering as a result of the Brownian motion of particles to estimate Z-average. Representative samples had been taken from each formula and diluted with water in ratio $1: 10 \mathrm{v} / \mathrm{v}$ as dispersant at $25{ }^{\circ} \mathrm{C}$ [15]. The results are the mean of three readings \pm standard deviation.

\section{Entrapment efficiency (EE)}

Samples from each formula were centrifuged at $15000 \mathrm{rpm}$ for 90 min at $4{ }^{\circ} \mathrm{C}$ using an ultra-cooling centrifuge for separation of supernatant containing a non-entrapped drug. After that, the supernatant was collected by micropipette and analyzed using a UV-
Visible spectrophotometer (UV-1800 spectrophotometer, Shimadzu, Kyoto, Japan) against a blank at the predetermined $\lambda_{\max }(284 \mathrm{~nm})$ to quantify the contribution of the components to UV absorption [16]. The amount of drug entrapped was expressed as a percentage (EE\%) and calculated from the following equation (equation 1):

$$
\mathrm{EE} \%=\frac{\mathrm{T}-\mathrm{F}}{\mathrm{T}} \times 100
$$

Where $\mathrm{T}$ is a total drug amount that theoretically present in the taken sample, $\mathrm{F}$ is the free drug amount that actually presents in the supernatant. The experiment was done in triplicate and represented as a mean \pm standard deviation

\section{Selection of the optimized formulation}

The desirability values were used as a differentiating parameter to compare between the different prepared formulations. The optimized formulation $\left(\mathrm{F}_{0}\right)$ was planned to be with the least PS and PDI in addition to the highest ZP and EE. The optimization of all responses was performed by calculating the overall desirability. Then, the optimized formulation was prepared and subjected to more characterization [17].

\section{Transmission electron microscopy (TEM)}

Morphological features of the optimized formulation were conducted to evaluate structural attributes including the lamellarity, uniformity of size and shape. In brief, one drop of appropriatelydiluted dispersion was spotted on a carbon-coated copper grid. The excess was removed using a filter paper, dried at room temperature and was stained with $2 \% \mathrm{w} / \mathrm{v}$ phosphotungstic acid for $10 \mathrm{~min}$, then washed with distilled water for three times and left to dry before the examination. Photomicrograph was taken by TEM (Philips $208 \mathrm{~S}$, USA.) [18] 


\section{Viscosity measurement}

The viscosity of the optimized formulation $\left(\mathrm{F}_{0}\right)$ was measured without dilution using cone and plate viscometer (Brookfield DV-III, USA) at $25 \pm 0.5^{\circ} \mathrm{C}$, attached with Spindle No CP42. The experiment was done in triplicate and represented as a mean \pm standard deviation.

\section{In vitro drug release study}

In vitro release study was carried out using vertical type Franz diffusion cells (Hanson research, Los Angeles, California, USA) with a $1 \mathrm{~cm}^{2}$ diffusion area. The optimized formulation $\left(\mathrm{F}_{0}\right)$ and the CBZ suspension equivalent to $5 \mathrm{mg}$ was placed in the donor compartment to compare the release of CBZ from the optimized vesicular structures and the CBZ suspension. The receptor compartment was filled using $7 \mathrm{ml}$ phosphate buffer at $\mathrm{pH} 6.8$, the temperature was maintained at $37 \pm 0.5{ }^{\circ} \mathrm{C}$ and the rotation was adjusted at $500 \mathrm{rpm}$. The formulation was separated from the receptor compartment using the cellophane membrane (Spectrum Medical Inc., Los Angeles, CA, USA cut-off 12,000-14,000).

Samples were withdrawn $(400 \mu \mathrm{l})$ at the following time intervals; $10,20,30,45,60,70,90,120,150$ and $180 \mathrm{~min}$ and were replaced with fresh buffer solution kept under the same conditions. The drug concentrations were analyzed using a UV spectrophotometer at predetermined $\lambda_{\max }$ (284) $\mathrm{nm}$. The readings are the mean of three experiments \pm standard deviation.

The percent of the drug release was calculated and plotted against time (min) for each of the optimized formulation and the pure CBZ suspension. The data obtained from the release study was subjected to kinetic analysis and the order of drug release was determined regarding zero and first-order kinetics as well as the Higuchi diffusion model.

\section{Physical stability study}

The optimized CBZ formulation $\left(\mathrm{F}_{0}\right)$ was kept for 6 mo in a tightly closed glass container at $25 \pm 2^{\circ} \mathrm{C}$. EE $\%$, PS and drug release were reevaluated at the end of the six months. The results were analyzed statistically using Design Expertsoftware (version10.0.1.0, Stat-Ease, Inc, USA). The difference was considered significant at $P \leq 0.05$. Similarity factor $\left(f_{2}\right)$ was used and the release of both, the fresh and the stored formulations was compared. Similarity factor was calculated according to Moore and Flanner model (1996) using the following equation (equation 2):

$$
\left.\mathrm{f} 2=50 \log \left\{\left[1+\left(\frac{1}{\mathrm{n}}\right) \sum_{\mathrm{t}=1}^{\mathrm{n}}(\mathrm{Rt}-\mathrm{Tt})\right]^{2}\right]^{-0.5} \mathrm{x} 100\right\}
$$

$\mathrm{R}_{\mathrm{t}}$ and $\mathrm{T}_{\mathrm{t}}$ are the percentages of CBZ released at time $t$ for fresh and test formulations, respectively, while $\mathrm{n}$ is the number of the sampling point. The release of both the fresh and the test formulations were considered similar when $f 2$ value falls within the range of 50-100.

\section{In vivo studies}

Based on the pharmaceutical in vitro evaluation, the optimized formulation $\left(\mathrm{F}_{0}\right)$ was selected for the in vivo evaluations in rats in comparison to oral CBZ suspension. All animal experiments were approved by the Pharmaceutical Ethical Committee of MSA University (PT 2/EC2/2017 PD).

Male Wistar rats weighing 220-250g, were purchased from the Egyptian Company for Production of Vaccines, Sera and Drugs (EGYVAC; Cairo, Egypt) and allowed free access to water and standard pellet chow. They were kept under constant conditions (temperature $25 \pm 3{ }^{\circ} \mathrm{C}$ and humidity $50 \%$ ) with $12 / 12 \mathrm{~h}$ light/dark cycles. The study was carried out according to the guidelines of the Ethics Committee, Faculty of Pharmacy, October University for Modern Sciences and Arts.

\section{Experimental design}

A preliminary study was carried out on 10 rats to determine the animals' behavior and survival rate after the administration of PTZ (50 mg/kg, i. p) [19]. This was achieved by observing the animals for $60 \mathrm{~min}$ following the injection of PTZ. The kindling score was recorded immediately after PTZ administration according to a prevalidated 5-point scoring scale 0 :no convulsion; 1:occasional body twitches; 2:partial clonic seizers in the body; 3:generalized clonic seizers; 4:tonic seizers).

In the main study, 32 rats were randomly divided into four groups, 8 rats in each group:

Group I: received normal saline to serve as a negative control group.

Group II: received a single dose of PTZ (50 mg/Kg; i. p) [19] dissolved in normal saline for the induction of kindling.

Group III: received oral CBZ $(20 \mathrm{mg} / \mathrm{kg}) 30 \mathrm{~min}$ before PTZ administration[20].

Group IV: received the optimized formulation $\left(\mathrm{F}_{0}\right)(1 \mathrm{mg} / \mathrm{kg}$; intranasal) in equal amount in both nostrils $20 \mathrm{~min}$ after PTZ administration.

After performing the behavioral tests, $60 \mathrm{~min}$ after PTZ administration, blood was collected from each rat aseptically by sterile disposable $3 \mathrm{ml}$ syringe through cardiac puncture for serum separation and estimation of the eNOS level. Rats were sacrificed using thiopental $(50 \mathrm{mg} / \mathrm{kg}$; i. p) [21] and brains were removed, cleaned with cold saline $(0.9 \%)$ and either fixed in $10 \%$ formalin for histopathological examination or homogenized in phosphate buffer saline to measure TNF- $\alpha$ and GSH content.

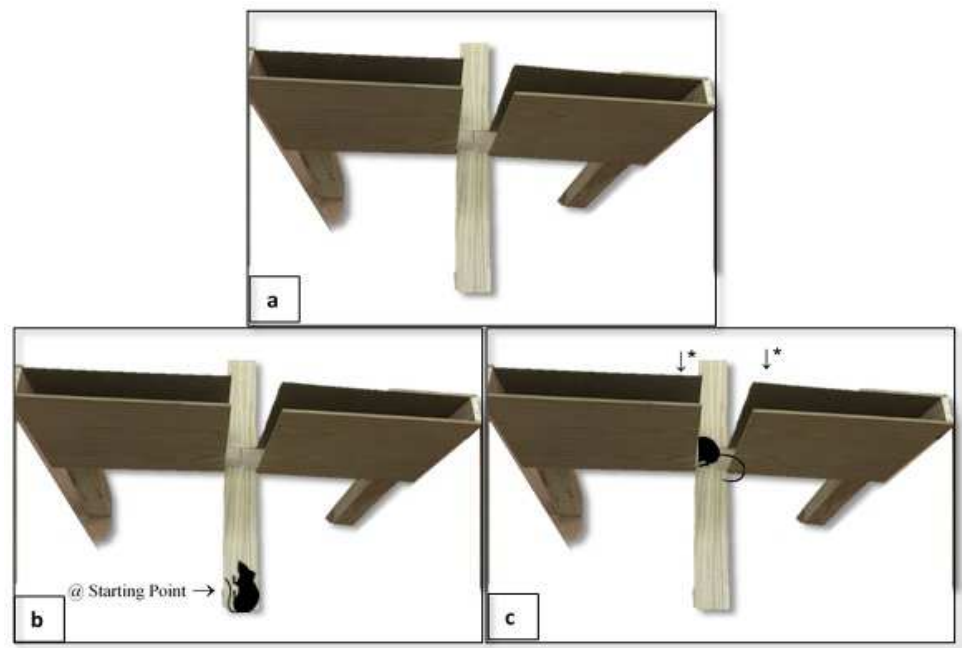

Fig. 1: Elevated plus maze device; fig. 1a: The maze is a wooden device consists of central platform $10 \times 10 \mathrm{~cm}$ with $10 \times 50 \mathrm{~cm}$ two open arms and two $10 \times 50 \times 40 \mathrm{~cm}$ closed arms with an open roof. Fig. 1b: Rats were individually placed at the distal end of the open arm (@) at $T_{20 \text { min, }} T_{30}$ min and $T_{40}$ min. Fig. $1 c$ : time taken for the rat entering to either of the closed arm $\left({ }^{*}\right)$ was recorded 


\section{Behavioral assessment by elevated plus maze test}

Kindling-induced cognitive impairment was assessed using elevated plus maze and passive avoidance test. The maze is a wooden device consisting of a central platform $(10 \times 10 \mathrm{~cm})$ with two open arms $(10 \times 50 \mathrm{~cm})$ and two closed arms with an open roof $(10 \times 50 \times 40$ $\mathrm{cm})$ as shown in fig. 1a. The height of the maze was $50 \mathrm{~cm}$ from the floor. Each rat underwent 3 trials. In the first trial, the rat was individually placed at the distal end of the open arm as shown in fig. $1 \mathrm{~b} 20 \mathrm{~min}$ after PTZ administration and the time taken for the rat to enter any of the closed arms were recorded as the initial transfer latency ( $\mathrm{T}_{20 \mathrm{~min}}$; fig. 1c). The second and third trials were performed similarly 30 and 40 min after PTZ administration and the retention transfer latency $\left(\mathrm{T}_{30} \mathrm{~min}\right)$ and $\left(\mathrm{T}_{40} \mathrm{~min}\right)$ were recorded respectively [22]. After each trial, the maze was cleaned with alcohol to remove confounding olfactory cues. A 90 seconds cut-off was set. To become familiar with the maze, rats were allowed to move freely in the maze after reaching the closed arm for another 10 seconds [23]

Determination of endothelial nitric oxide synthase (e-NOS), reduced glutathione (GSH) and ELISA estimation of the TNF $\alpha$

Level of e-NOS $(\mathrm{ng} / \mathrm{ml})$ was measured based on serum by diazotization of sulfanilic acid by nitric oxide at acid $\mathrm{pH}$ and successive coupling to N-1-naphthyl ethylenediamine [24]. For estimation of reduced Glutathione (GSH) $\mathrm{mg} / \mathrm{g}$ tissue content and TNF- $\alpha$ tissue content $(\mathrm{Pg} / \mathrm{mg}$. Tissue), ELISA technique using standard kits (My BioSource, Inc., USA) were used.

\section{Histological examination}

Brain tissues fixed in 10\% formalin and embedded in paraffin wax, were sonicated at $6 \mu \mathrm{m}$ thickness on a rotatory microtome, then stained with eosin and hematoxylin and Cresyl violet [25]. The stained sections were observed using the digital microscope and digital photomicrographs by using the attached camera.

\section{RESULTS AND DISCUSSION}

\section{Characterization of the prepared vesicles}

\section{Analysis of $2^{3}$ multifactorial design}

The multifactorial design shows a useful and effective method to develop the optimized formulation due to its ability to analyze the effect of independent variables on the characteristics of the formulations[26]. The composition of the eight formulations was represented in table 1 according to $2^{3}$ multifactorial design, in addition to the measured responses using Design-Expert 10.0.1.0 ${ }^{\circledR}$ software. In the present research, the effect of formulation independent variables on the dependent responses (PS, PDI, ZP and $\%$ EE) was graphically illustrated as 3-D plot and the desirability was illustrated as a normal plot in fig. 2 and fig. 3 , respectively.

\section{The effect of independent formulation variables on particle size} (PS)

PS has considered an important parameter in the niosomes and the spanlastics preparation as the PS affects the drug release and the permeability of the vesicular structures. The PS of the formulated vesicular structures ranged from $263 \mathrm{~nm}$ to $2990 \mathrm{~nm}$ as shown in table 1 . The results of the PS are represented in the following equation (3) for both niosomes and spanlastics formulations

The response $Y_{1}$ which is the vesicles PS is represented by the following polynomial equation (equation 3 ):

$$
\begin{aligned}
\mathrm{Y} 1=+1062.09+104.68 \mathrm{XA}-705.79 \mathrm{XB}-430.50 \mathrm{XC} \\
-121.63 \mathrm{XA} * \mathrm{~B}-8.67 \mathrm{X} \mathrm{AC}+428.85 \mathrm{XBC}
\end{aligned}
$$

- For niosomes represented in equation 4 :

$\mathrm{PS}=+1767.88+226.31 \mathrm{XA}-859.35 \mathrm{XC}-8.67 \mathrm{XAC}$

- For spanlastics represented in equation 5 :

PS $=+356.30-16.95 \mathrm{XA}-1.65 \mathrm{XC}-8.67 \mathrm{XAC}$

According to equation (4), the positive value of drug's percent $X_{A}$ reveals that the increases of drug's percent will lead to increase the
PS of niosomes as the more increase in CBZ's percent, the more encapsulation of CBZ into the vesicle. This is because of the probability of the interaction between the CBZ, the surfactant head groups and the interaction with cholesterol which leads to the increase of the PS. While with spanlastics the more increase the drug's percent, the more decrease the PS due to the absence of cholesterol as shown by the negative coefficient of $\mathrm{X}_{\mathrm{A}}$ in equation (5) [27]. The negative coefficient with cholesterol of $X_{c}$ reveals that, increasing the speed of rotation lead to the decrease the PS of both noisome and spanlastics. This is due to the formation of a thin uniform lipid layer result in the spherical vesicles upon the hydration of the vesicles [28]

Equation (3) shows that PS is affected adversely by the presence of the vesicles of niosomes and spanlastics as can be deduced from the negative coefficient of $X_{B}$. Spanlastics have smaller PS than niosomes and this due to; spanlastics is prepared by using span 60 which has low hydrophilic-lipophilic balance (HLB) leading to decrease the surface energy and formation a smaller PS. Also, it contains polyvinyl alcohol which contributing to this small size by reducing the membrane [29]. On the other hand, Niosomes prepared by using cholesterol which makes a rigid bilayer through reducing the vesicle's phase transition temperature peak and increasing the liquid bilayer's chain [30,31]. As showed in equation (3) and table 2 , the PS of both the niosomes and spanlastics is significantly affected by all factors except $X_{A C}$ which has an insignificant effect on PS as shown in equation (4) and (5).

The effect of independent formulation variables on the polydispersity index (PDI)

PDI refers to the vesicle size's uniformity within the formulation. PDI is used as a measure for the formulation homogeneity. It is calculated through the ratio of the standard deviation to the mean vesicle size. The higher of the PDI, the lower of the vesicle size's uniformity [32]. The PDI for the prepared formulation ranged from 0.594-0.99 as shown in table 1.

The response $Y_{2}$ which is the PDI is represented by the following polynomial equation (equation 6):

$$
\begin{gathered}
\mathrm{Y} 2=+0.80-0.015 \mathrm{XA}+0.10 \mathrm{XB}+0.061 \mathrm{XC}-0.015 \mathrm{XAB} \\
+0.018 \mathrm{XAC}-0.028 \mathrm{XBC}
\end{gathered}
$$

- For niosomes represented in equation 7:

$$
\mathrm{PDI}=+0.70+3.75 \mathrm{E}-004 \mathrm{XA}+0.08 \mathrm{XC}+0.018 \mathrm{XAC}
$$

- For spanlastics represented in equation 8:

PDI $=+0.90-0.029 \mathrm{X}_{\mathrm{A}}+0.033 \mathrm{X}_{\mathrm{C}}+0.018 \mathrm{X}_{\mathrm{AC}}$

As shown in table 2, PDI is significantly affected by all factors except $\mathrm{X}_{\mathrm{A}}, \mathrm{X}_{\mathrm{AB}}$, and $\mathrm{X}_{\mathrm{AC}}$ which have an insignificant effect on PDI.

According to equations (7) and (8), the positive coefficient of $\mathrm{X}_{\mathrm{C}}$ reveals that increasing the speed of rotation increases the PDI of both noisome and spanlastics. This is due to the formation of a thin uniform lipid layer that results in the formation of spherical vesicles upon the hydration of both vesicles which leads to increase the PDI [28].

As shown in equation (6), the positive coefficient $\left(X_{B}\right)$ reveals that PDI is affected by the presence of the vesicular structure of both niosomes and spanlastics. Niosomes have larger PS so they show lower PDI. On the other hand, spanlastics which have smaller PS show larger PDI that may be due to the difference in composition between both types of vesicular structures [33].

The effect of independent formulation variables on the zeta potential (ZP)

ZP measures the repulsion's degree between the same charged particles in the dispersion system and this will determine the vesicle's stability [34]. The ZP ranged from-4.63 mV-60.6 mV as represented in table 1 . ZP is significantly affected by all factors except $X_{A B}$ which has an insignificant effect on $\mathrm{ZP}$ as shown in table 2

The final equation in terms of coded factors for ZP is represented by the following polynomial equation (equation 9) 


$$
\begin{gathered}
\mathrm{Y3}=+28.31+5.86 \mathrm{XA}-19.79 \mathrm{XB}+5.03 \mathrm{XC}-4.74 \mathrm{XAB} \\
-5.09 \mathrm{XAC}-6.75 \mathrm{XBC}
\end{gathered}
$$

- For niosomes represented in equation 10

$\mathrm{ZP}=+48.10000+10.60000 \mathrm{XA}+11.77500 \mathrm{XC}-5.08500 \mathrm{XAC}$

- For spanlastics represented in equation 11

$\mathrm{ZP}=+8.51250+1.12500 \mathrm{XA}-1.71750 \mathrm{XC}-5.08500 \mathrm{XAC}$

The ZP significantly is affected by all factors as showed in table 2 . According to equation (10) and (11), the positive coefficient $\left(\mathrm{X}_{\mathrm{A}}\right)$ reveals that the increase in drug's percent results in the increase in ZP's values for both niosomes and spanlastics. This may be because of the probability of the interaction between the CBZ and the surfactant head groups which increase the surfactant bilayer's charge and the mutual repulsion between the particles.

According to equation (10), the positive coefficient $\left(\mathrm{X}_{\mathrm{C}}\right)$ revealed that the more increase in the speed of rotation in niosomes, the more increase in the ZP and the more stability will be achieved this could be due to the formation of a thin film that prevents the formation of aggregation and achieves higher repulsion between the particles [28]. On the other hand, increasing the speed of rotation leads to a decrease in the ZP in the spanlastics. According to equations (10) and (11), decreasing the ratio of both drug's percent and rotation's speed leads to an increase the ZP for both Niosomes and spanlastics.

Equation (9) showed the negative coefficient of $X_{B}$ which show that ZP is affected by the type of the vesicles whether niosomes or spanlastics which can be attributed to the presence of edge activator which causes the accumulation of hydrophilic edge activator on the surface of the vesicular layers leading to the decrease in the $\mathrm{ZP}$ in case of spanlastics [35].

The effect of independent formulation variables on entrapment efficiency (\%EE)

$\mathrm{EE}$ is an important parameter in the vesicular formulation's design. The more the EE, the more drug's bioavailability and also the higher the drug's concentration will be targeted to the specific site leading to decrease in the required dose [32]. The EE ranges for all prepared formulations was ranged from $44 \%-97.6 \%$.

Final equation in terms of coded factors for EE is represented by the following polynomial equation (equation 12)

$\mathrm{Y} 4=+83.80+7.23 \mathrm{XA}-12.87 \mathrm{XB}-1.83 \mathrm{XC}+6.59 \mathrm{XAB}+$ $4.95 \times \mathrm{XAC}-1.60 \mathrm{XBC}$

- For niosomes represented in equation 13

$\mathrm{EE}=+96.67+0.64 \mathrm{XA}-0.22 \mathrm{XC}+4.94 \mathrm{XAC}$

- For spanlastics represented in equation 14

$$
\mathrm{EE}=+70.92+13.82 \mathrm{XA}-3.42 \mathrm{XC}+4.94 \mathrm{XAB}
$$

According to equations (13) and (14), the positive coefficient of $\mathrm{X}_{\mathrm{A}}$ reveals that the EE increased as the drug amount which is used to load the niosomes or the spanlastics increased. This is may be due to the increase in the medium's saturation with the drug which will then be available to be encapsulated into the vesicles [32].

As shown in table 2, the EE is insignificant for $\mathrm{X}_{\mathrm{AB}}$ as the $p$-value is $>0.05$ ).

The EE of niosomes is higher than that of spanlastics, this may be attributed to the EE of noisome will be affected by both components; cholesterol and span 60. Cholesterol increases the membrane's rigidity by increasing the membrane bilayer hydrophobicity making it more rigid and this will prevent the drug's leakage [36]. While the spanlastics showed lower EE than niosomes this may refer to the presence of span 60 and absence of cholesterol. Span 60 has a low HLB value (5.3), long carbon chain (C16) and it has a high phase transition temperature which decreases the leakage and the fluidity of the bilayer that leads to lower EE [33, 37].

The Pred. $\mathrm{R}^{2}$ for PS, PDI, ZP and EE was found to be $0.96,0.94,0.86$ and 0.76 , respectively and in reasonable agreement with the Adj. $\mathrm{R}^{2}$ of $0.98,0.94,0.89$ and 0.89 for PS, PDI, ZP and EE, respectively.
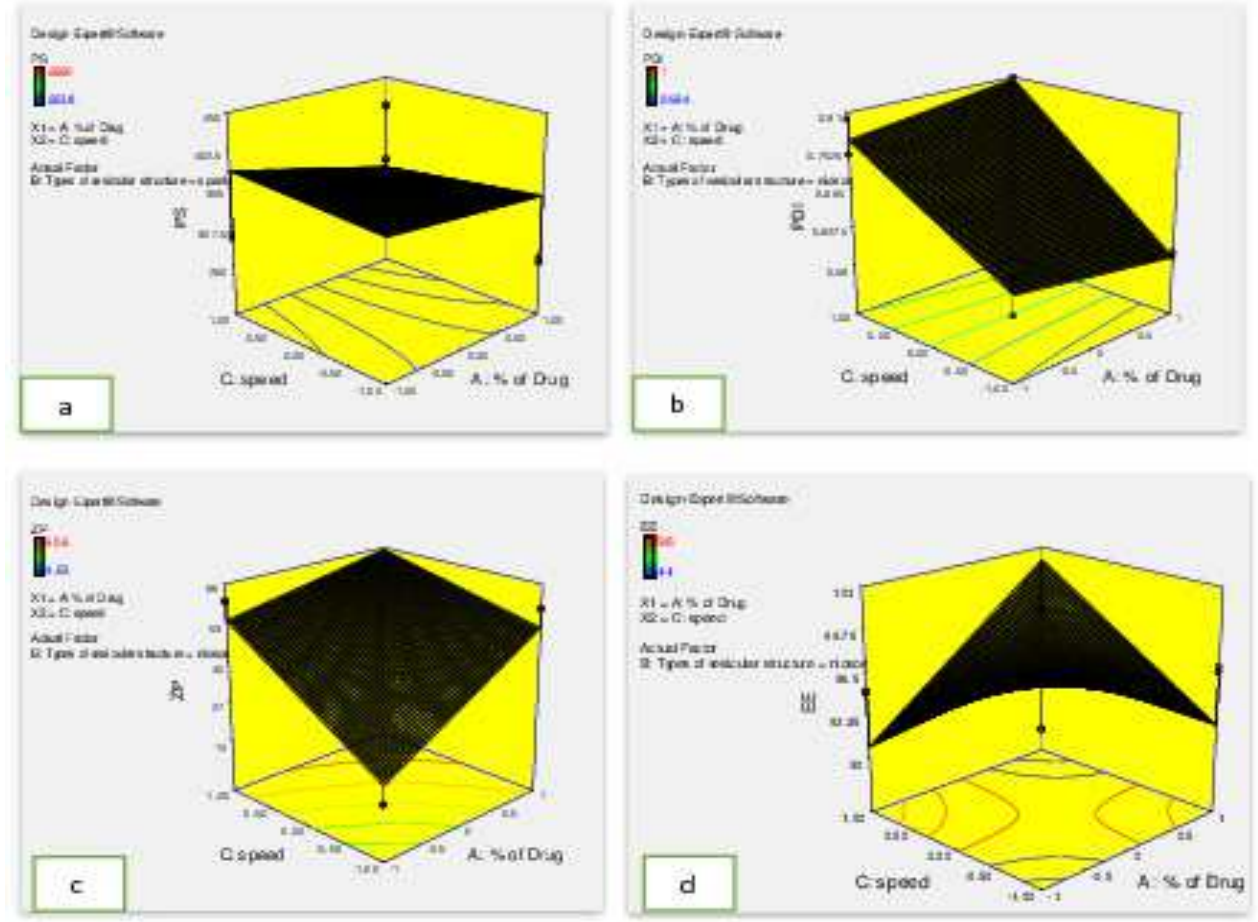

Fig. 2: 3D surface plot of (a) PS, (b) PDI, (c) ZP and (d) EE\% of niosomes and spanlastics 

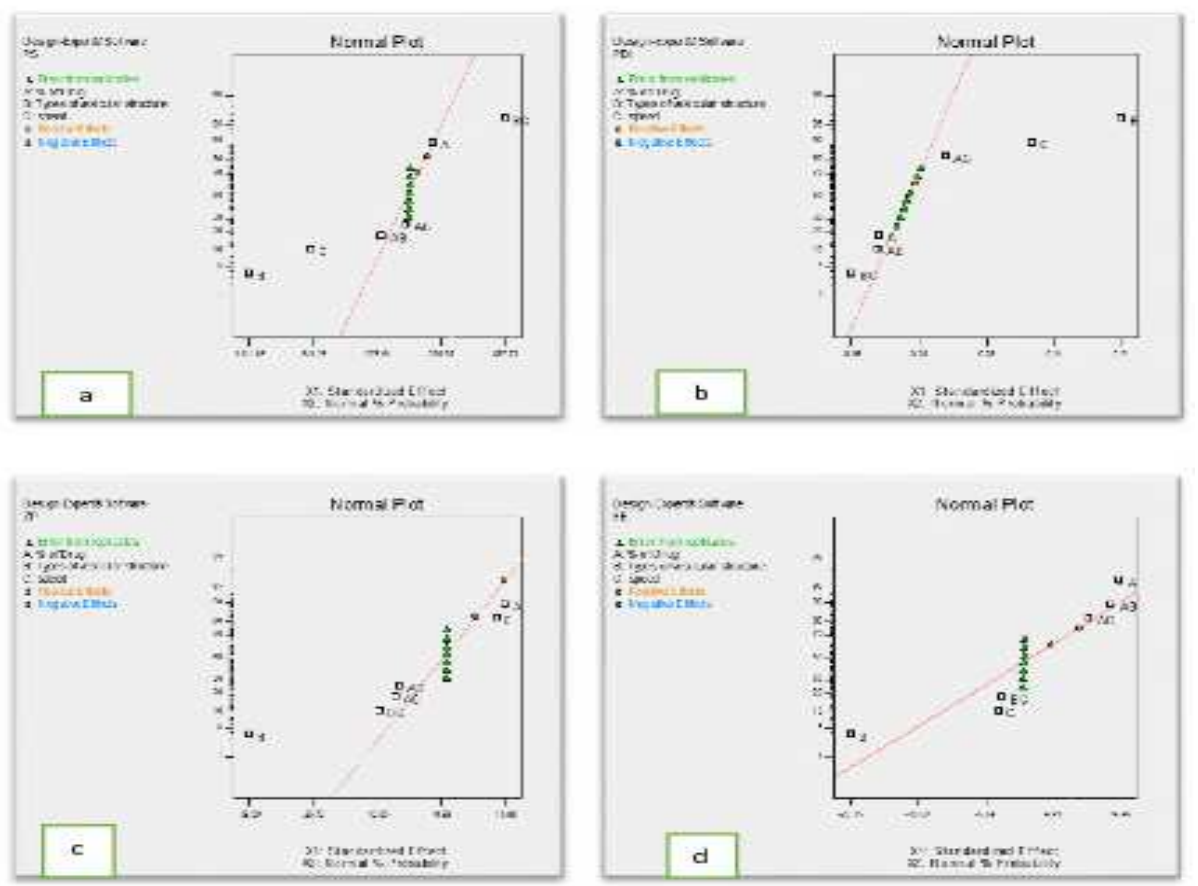

Fig. 3: Normal probability plot of niosomes and spanlastics formulae to screen the influence of (a) PS, (b) PDI, (c) ZP and (d) EE\%

Table 2: Sum of squares, degree of freedom (df), mean squares, F-value for the model coefficients estimated from the factorial design for (a)PS, (b) PDI, (c) ZP and (d) EE\% of niosomes and spanlastics

\begin{tabular}{|c|c|c|c|c|c|c|}
\hline & Source & Sum of squares & df & Mean square & F value & $p$-value Prob $>F^{*}$ \\
\hline & A-\% of Drug & $1.753 \mathrm{E}+005$ & 1 & $1.753 \mathrm{E}+005$ & 12.36 & 0.0079 \\
\hline \multirow[t]{5}{*}{ PS } & B-Types of vesicular structure & $7.970 \mathrm{E}+006$ & 1 & $7.970 \mathrm{E}+006$ & 561.61 & $<0.0001$ \\
\hline & C-speed of rotation & $2.965 E+006$ & 1 & $2.965 E+006$ & 208.95 & $<0.0001$ \\
\hline & $A B$ & $2.367 \mathrm{E}+005$ & 1 & $2.367 \mathrm{E}+005$ & 16.68 & 0.0035 \\
\hline & $A C$ & 1203.05 & 1 & 1203.05 & 0.085 & 0.7783 \\
\hline & $B C$ & $2.943 E+006$ & 1 & $2.943 E+006$ & 207.35 & $<0.0001$ \\
\hline \multirow[t]{7}{*}{ PDI } & A-\% of Drug & 3.393E-003 & 1 & 3.393E-003 & 2.97 & 0.1230 \\
\hline & B-Types of vesicular structure & 0.17 & 1 & 0.17 & 153.22 & $<0.0001$ \\
\hline & $C$-speed of rotation & 0.059 & 1 & 0.059 & 52.04 & $<0.0001$ \\
\hline & $A B$ & 3.570E-003 & 1 & $3.570 \mathrm{E}-003$ & 3.13 & 0.1150 \\
\hline & $A C$ & $5.293 \mathrm{E}-003$ & 1 & $5.293 \mathrm{E}-003$ & 4.64 & 0.0635 \\
\hline & $B C$ & 0.012 & 1 & 0.012 & 10.94 & 0.0107 \\
\hline & A-\% of Drug & 549.90 & 1 & 549.90 & 7.78 & 0.0236 \\
\hline \multirow[t]{6}{*}{$\mathrm{ZP}$} & B-Types of vesicular structure & 6268.68 & 1 & 6268.68 & 88.67 & $<0.0001$ \\
\hline & C-speed of rotation & 404.61 & 1 & 404.61 & 5.72 & 0.0437 \\
\hline & $A B$ & 359.10 & 1 & 359.10 & 5.08 & 0.0542 \\
\hline & $A C$ & 413.72 & 1 & 413.72 & 5.85 & 0.0419 \\
\hline & $B C$ & 728.19 & 1 & 728.19 & 10.30 & 0.0124 \\
\hline & A-\% of Drug & 836.94 & 1 & 836.94 & 23.18 & 0.0013 \\
\hline \multirow[t]{5}{*}{$\% \mathrm{EE}$} & B-Types of vesicular structure & 2651.22 & 1 & 2651.22 & 73.44 & $<0.0001$ \\
\hline & C-speed of rotation & 53.36 & 1 & 53.36 & 1.48 & 0.2587 \\
\hline & $A B$ & 695.38 & 1 & 695.38 & 19.26 & 0.0023 \\
\hline & $A C$ & 391.45 & 1 & 391.45 & 10.84 & 0.0110 \\
\hline & $B C$ & 40.90 & 1 & 40.90 & 1.13 & 0.3182 \\
\hline
\end{tabular}

*Values of "Prob $>$ F" less than 0.05 indicate model terms are significant.

\section{Optimization}

The Design-Expert 10.0.1.0 ${ }^{\circledR}$ software suggested one spanlastics optimized formulation. The composition of the optimized formulation was based on selecting the lowest PS, lowest PDI, highest ZP and highest EE. The compositions of the prepared CBZ optimized formulation $\left(\mathrm{F}_{\mathrm{o}}\right)$ was represented in table 3 , in addition to the observed and predicted responses. The predicted value for PS, PDI, ZP, and the EE\% were $350.09 \mathrm{~nm}, 0.830,16.124 \mathrm{mV}$ and
$82.777 \%$, respectively. The experimentally observed results were in reasonable agreement with the model prediction; thus, the validity of the model was established. The optimized spanlastics formulation $\left(\mathrm{F}_{0}\right)$ was prepared and formulated using the same method and under the same conditions of the originally prepared experimental formulations (F1-F8), then further investigations were carried on the optimized spanlastics formulation $\left(\mathrm{F}_{0}\right)$. The $3-\mathrm{D}$ plot and the desirability were illustrated as a normal plot in fig. $4 \mathrm{a}$ and fig. $4 \mathrm{~b}$, respectively. 
Table 3: The predicted, observed and $\%$ biased of the optimized formulation (Fo)

\begin{tabular}{|c|c|c|c|c|}
\hline Composition of the optimized formulation $\left(F_{0}\right)$ & Dependent variables & Predicted & Observed & \% Biased ${ }^{*}$ \\
\hline $\mathrm{X}_{1}=0.95$ & PS (nm) & 350.09 & 360 & -2.75 \\
\hline $\mathrm{X}_{2}=$ Spanlastics & PDI & 0.830 & 0.89 & -6.74 \\
\hline$X_{3}=-1.00$ & $\mathrm{ZP}(\mathrm{mv})$ & -16.124 & -14.7 & 9.68 \\
\hline & EE $(\%)$ & 82.777 & 85.6 & -3.29 \\
\hline
\end{tabular}

*\% Biased $=($ Predicted-Observed $) /$ Observed
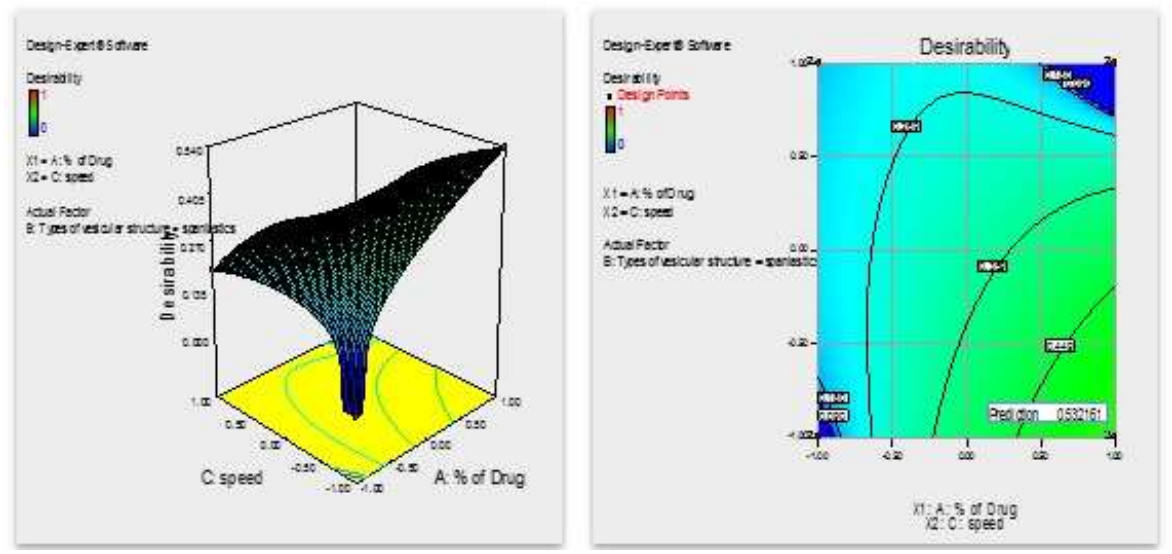

Fig. 4: (a) 3-D surface plot and (b) Normal plot of the optimized formula ( $\left.F_{0}\right)$

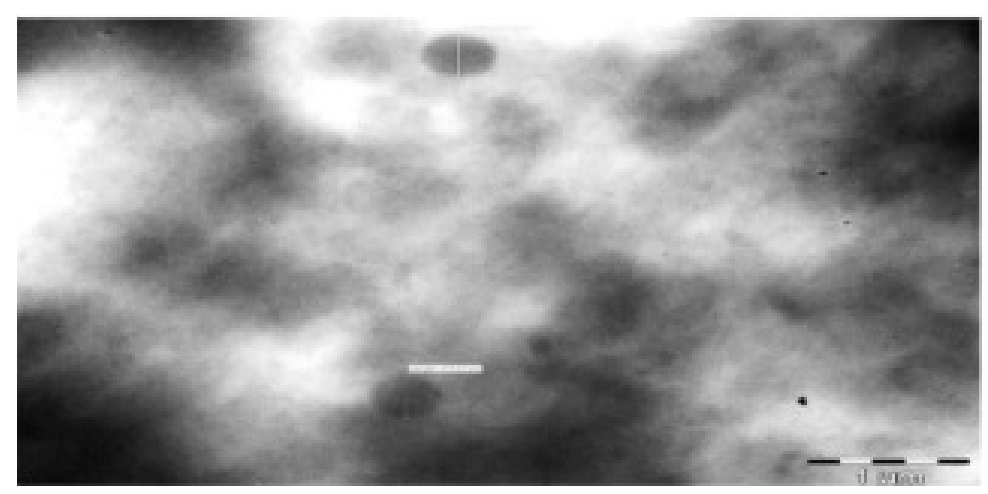

Fig. 5: TEM micrograph of the optimized formulation $\left(F_{0}\right)(P S=418.83 \mathrm{~nm})$

\section{Transmission electron microscopy (TEM)}

The photomicrograph of the optimized spanlastics formulation was taken by the transmission electron microscopy (TEM) as shown in fig. 5 . The photomicrograph reveals the spherical shape of the optimized spanlastics formulation. The structure of well-identified sealed spherical vesicles was noticed which are nearly homogenous in shape [38].

\section{Viscosity measurement}

The viscosity of the CBZ optimized spanlastics formulation was studied as an indication for the in vitro prolong retention after administration via the intranasal route. The viscosity was nearly uniform and constant through the whole shear rate values (nearly $65 \mathrm{cps}$ ). This nearly high viscosity due to the presence of two highly viscous surfactants in the composition of spanlastics formulation so that the prepared formulation could be used without the need of incorporating a gelling agent [13]. The almost constant viscosity indicated that the flow of the optimized formulation is Newtonian flow.

\section{In vitro drug release study}

In vitro release study was carried out using vertical type Franz diffusion cells (Hanson research, Los Angeles, California, USA) with a 1 $\mathrm{cm}^{2}$ diffusion area. The CBZ optimized spanlastics formulation and the CBZ suspension release were compared in order to study the effect of formulation on drug release, results are represented in fig. 6. The amount of CBZ (95.85\%) was detected in the tested medium after 180 min. The results demonstrated the ability of the optimized spanlastics formulation to increase drug release in the range time from 10-60 min $(\mathrm{p}<0.05)$ when compared with the release of CBZ suspension. While after $90 \mathrm{~min}$ the release showed almost the same profile and no significant difference was noticed at the end of the release profile ( $p>0.05$ ), while for the CBZ suspension the release profile showed the release of $61.11 \%$ after $180 \mathrm{~min}$. This might be due to the vesicular structure of spanlastics and the incorporation of span 60 and polyvinyl alcohol which can improve the release of the CBZ from the vesicles [12, 32]. Both formulations were found to fit the Higuchi diffusion equation with " $r$ " values of 0.976 and 0.992 for the optimized spanlastics formulation and CBZ suspension, respectively.

\section{Physical stability study}

The appearance of the CBZ optimized spanlastics formulation (Fo) showed no visual change during the six-month period of storage at $25^{\circ} \mathrm{C}$. Table 4 represents the measured parameters of the EE\%, the PS and the release after one $\mathrm{h} \mathrm{Q} 1$, the results of the stored optimized formulation showed no significant difference ( $p>0.05$ ) when compared with the fresh formulation. Fig. 7 showed that the stored and the fresh formulation were almost similar. The similarity factor $(f 2)$ was found to be 68 which indicates that the storage condition did not affect the drug [38]. 


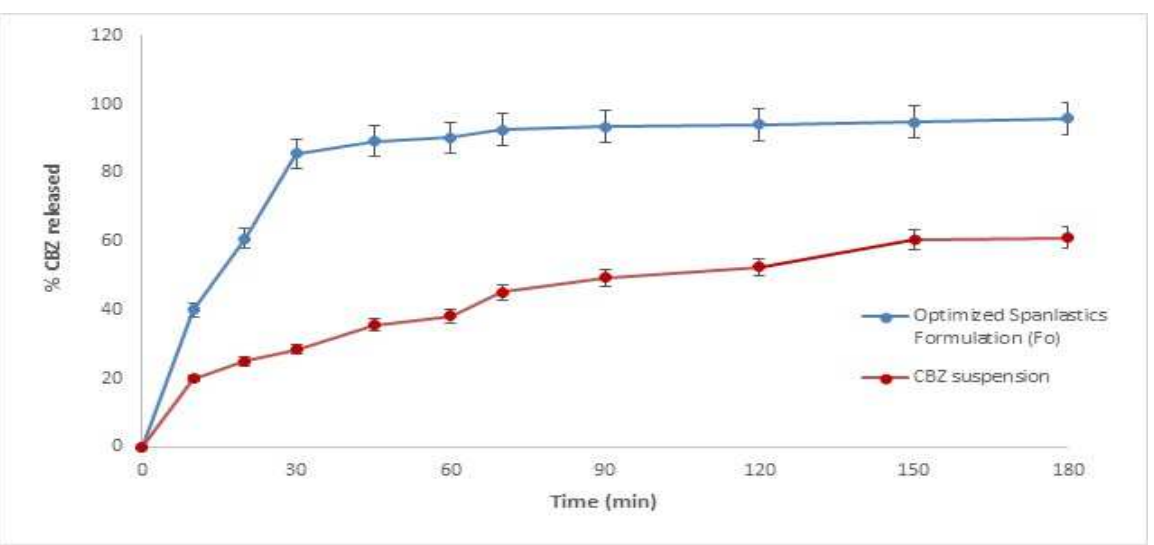

Fig. 6: In vitro release profiles of $\mathrm{CBZ}$ from the optimized spanlastics formulation $\left(\mathrm{F}_{0}\right)$ and $\mathrm{CBZ}$ suspension in phosphate buffer pH 6.8 (The results are mean $\pm S D, n=3$ )

Table 4: The effect of storage on the EE\%*, PS* and the drug release at Q1* for the optimized spanlastics formulation

\begin{tabular}{|c|c|c|}
\hline Parameters & Fresh formulation & Stored formulation after $6 \mathrm{mo}$ at $25^{\circ} \mathrm{C}$ \\
\hline EE\%* & $85.6 \pm 0.22$ & $82.4 \pm 0.45$ \\
\hline PS* (nm) & $360 \pm 4.14$ & $375 \pm 5.34$ \\
\hline Q1 h*(\%) & $90.22 \pm 2.32$ & $95.05 \pm 3.56$ \\
\hline
\end{tabular}

The results are mean $\pm \mathrm{SD}(\mathrm{n}=3), \mathrm{EE} \% *$ : Entrapment efficiency percent, $\mathrm{PS}^{*}$ : particle size and Q1*: the drug release after $1 \mathrm{~h}$

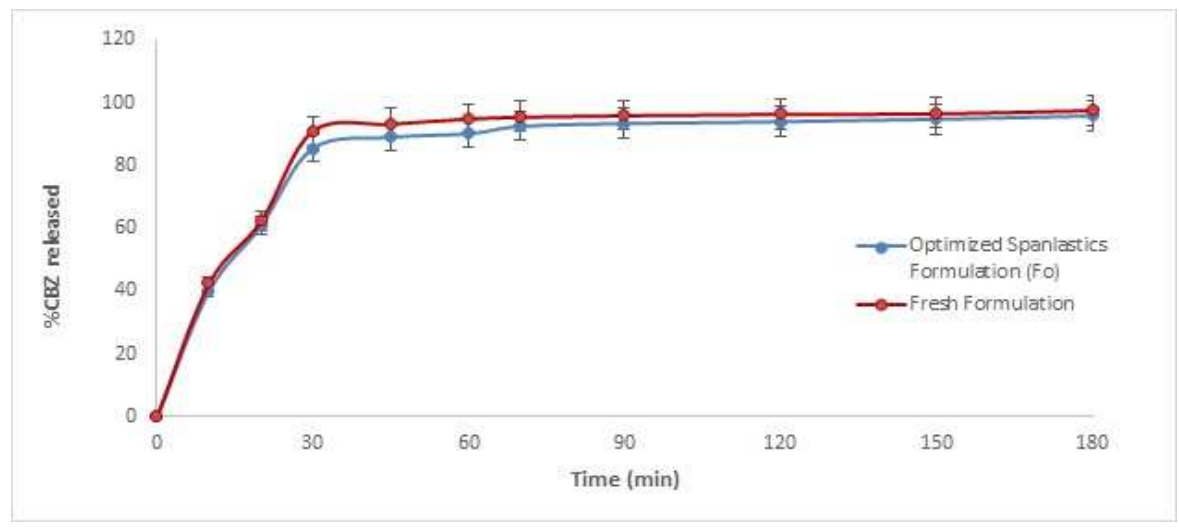

Fig. 7: In vitro release profiles of CBZ from the optimized spanlastics formulation (Fo) and CBZ fresh formulation in phosphate buffer pH 6.8 after $6 \mathrm{mo}$ at $25^{\circ} \mathrm{C} \pm \mathrm{SD}$. (The results are mean $\pm \mathrm{SD}, \mathrm{n}=3$ )

\section{In vivo studies}

The results of the preliminary study revealed that approximately $80 \%$ of the animals survived in the first $60 \mathrm{~min}$ of the experiment. In the first $10 \mathrm{~min}$, the animals did not display any convulsions and were assigned a kindling score 0; however, during the following $10 \mathrm{~min}$ (from 10-20 $\mathrm{min}$ ), the animals started to exhibit some convulsions and were assigned kindling score 1 . Meanwhile, from 20 to $40 \mathrm{~min}$ the severity of the convulsions increased and was given a kindling scored 3 . Only $20 \%$ of the animals experienced generalized clonic seizures (score 4) and died in the last $10 \mathrm{~min}$ of the experiment. Based on these observations, an elevated plus maze test was used to observe the animal's latency to reach any of the closed arms at $\mathrm{T}_{20 \mathrm{~min}}, \mathrm{~T}_{30 \mathrm{~min}}$ and $\mathrm{T}_{40}$ min after pentylenetetrazol (PTZ) administration.

\section{Behavioral assessment by elevated plus maze test}

Animals groups received either saline, intraperitoneal PTZ, oral CBZ or intranasal CBZ. Latency time was recorded after $20 \mathrm{~min}, 30 \mathrm{~min}$, and $40 \mathrm{~min}$ after PTZ administration. The rats in the normal control group (group I) reached the closed arm at $\mathrm{T}_{20 \mathrm{~min}}, \mathrm{~T}_{30 \mathrm{~min}}$, and $\mathrm{T}_{40 \mathrm{~min}}$ within a latency of $8.125,7.916$, and 8.25 seconds respectively. Rats injected with PTZ (group II) displayed a delay in latency time by 319 $\%$ at $\mathrm{T}_{20}$ min this delay was due to the small tremors (score 1 ) that started $10 \mathrm{~min}$ after PTZ administration. However, after $30 \mathrm{~min}$ (score 2) and 40 min (score 3), PTZ injected rats demonstrated some clonic convulsions which resulted in a further delay in latency time by 9.35 and 12 folds, respectively compared to the normal control group. The administration of either oral CBZ (group III) or intranasal optimized formulation $\mathrm{F}_{0}$ (group IV) improved latency time compared to untreated rats. However, the effect of the intranasal dosage form was more pronounced resulting in a $31 \%$ decrease in latency time at $\mathrm{T}_{30 \min }$ and $43 \%$ at $\mathrm{T}_{40 \mathrm{~min}}$ compared to the oral dosage form. Values are expressed as mean \pm S. E ( 8 animals). Statistical analysis was performed using the one-way ANOVA followed by Tukey's post hoc test $(P<0.05)$ where $(a)$ significant difference from normal control group, (b) PTZ control and (c) CBZ oral. $\mathrm{T}_{20}$ min: latency time after 20 min of PTZ administration; $\mathrm{T}_{30} \mathrm{~min}$ : latency time after $30 \mathrm{~min}$ of PTZ administration and $\mathrm{T}_{40 \mathrm{~min}}$ : latency time after 40 min of PTZ administration as shown in fig. 8. This is revealed to the rapid CBZ release from the optimized spanlastic formulation and the rapid absorption of the $\mathrm{CBZ}$ from the nasal route to reach rapidly the brain via the olfactory region. 


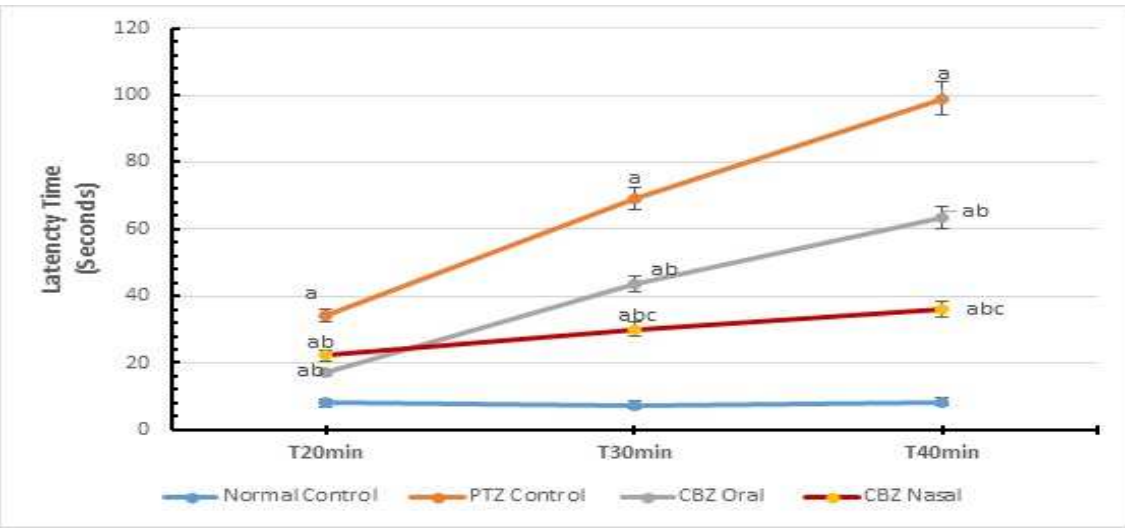

Fig. 8: Elevated plus maze test for normal control, $P T Z$ positive control, $C B Z$ oral group and $C B Z\left(F_{0}\right)$ nasal spanlastic group, a: significantly different from normal the control group at $P \leq 0.05$. b: significantly different from the PTZ control group at $P \leq 0.05$. c: significantly different from CBZ oral group at $P \leq 0.05$, Data are presented as the mean \pm SE Statistical analysis was carried out by one-way analysis of variance (ANOVA) followed by Tukey-Kramer test for multiple comparisons

Determination of serum endothelial nitric oxide synthase (eNOS), tissue reduced glutathione (GSH) and ELISA estimation of tissue TNF $\alpha$

PTZ injected rats exhibited an increase in brain inflammation as manifested by the significant increase in TNF- $\alpha$ as compared to the normal control group as represented in table 5 . This increase has also been reported in previous studies $[39,40]$. In the present study,the administration of CBZ by either route significantly decreased TNF- $\alpha$ content in the brain tissue as compared to the PTZ control group. Oral administration of CBZ is known to present antiinflammatory effects, these effects might be accredited to the ability of CBZ to block Na channels [41]. Nevertheless, rats which received intranasal CBZ displayed a better anti-inflammatory effect as depicted by the decrease in brain content of TNF- $\alpha$ as compared to oral CBZ. In addition, rats on intranasal dosage form displayed enhanced antioxidant activity as evident by the increase in the brain content of GSH. Similarly, serum eNOS was significantly increased in the PTZ control group as compared to normal control rats. This increase can be attributed to the acute inflammatory state created by the epileptic seizures that were detected in the current as well as previous studies where eNOS expression has been shown to be increased in endothelial and Schwann cells of sciatic nerves during experimental autoimmune neuritis [42]. Epileptic seizures by itself can induce an increase in NO production, and this increase may be involved in seizure-induced neurodegeneration [43]. In the present study, the administration of CBZ attenuated the PTZ-induced increase in eNOS. Although the effect on nasal CBS was more pronounced than oral CBZ, yet the difference was not statistically significant.

Table 5: The effect of oral CBZ and intranasal CBZ on serum level of endothelial nitric oxide synthase (eNOS) and brain content of tumor necrosis factor alpha (TNF- $\alpha$ ) and glutathione (GSH) in PTZ-induced epilepsy in rats

\begin{tabular}{llll}
\hline Parameters groups & Serum Enos $(\mathbf{n g} / \mathbf{m l})$ & Brain TNF- $\boldsymbol{\alpha}(\mathbf{P g} / \mathbf{m g})$ & Brain GSH $(\mathbf{m g} / \mathbf{g})$ \\
\hline Normal Control & $2.000 \pm 0.134$ & $86.070 \pm 2.630$ & $275.315 \pm 6.701$ \\
PTZ Control & $5.95 \pm 0.380^{\mathrm{a}}$ & $127.555 \pm 0.704^{\mathrm{a}}$ & $161.510 \pm 5.237^{\mathrm{a}}$ \\
CBZ Oral & $3.650 \pm 0.201^{\mathrm{ab}}$ & $107.600 \pm 2.111^{\mathrm{ab}}$ & $211.795 \pm 5.118^{\mathrm{ab}}$ \\
CBZ Nasal & $2.950 \pm 0.190^{\mathrm{b}}$ & $96.270 \pm 3.568^{\mathrm{abc}}$ & $257.120 \pm 5.720^{\mathrm{bc}}$ \\
\hline
\end{tabular}

Values are expressed as mean \pm S. E ( 8 animals). Statistical analysis was performed using one-way ANOVA followed by Tukey's post hoc test $(P<0.05)$, where(a) significant difference from the normal control group, (b) PTZ control and (c) CBZ oral.
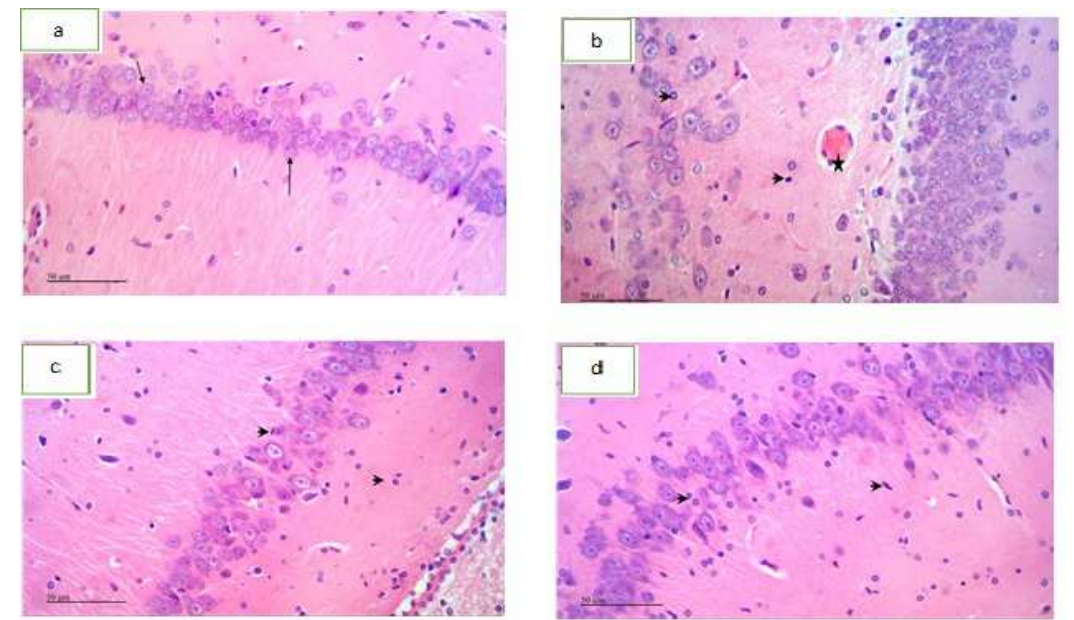

Fig. 9: Histopathological images of brain tissue sections: (a) examination of normal brain negative group showed intact neurons in the different layers $(\rightarrow)$. (b) Positive control group showed single scattered degeneration $(\star)$ and glial cells infiltration ( $\rightarrow$ ). (c) Oral CBZ showed mild glial cells infiltration $(\rightarrow)$. (d) Optimized intranasal $\left(F_{0}\right)$ showed almost intact neurons $(\rightarrow)$ 


\section{Histological examination}

The histopathological image for the brains of the rats in the normal control group I showed intact neurons in the different layers and zones of the hippocampus (hilus and fascia dentata) $(\rightarrow)$ in addition to the recorded large vesicular nuclei in cornu ammonis (CA) zone (fig. 9a). PTZ administration group II caused a single scattered degeneration $(\star)$ in some neurons in the layer of CA zone with pyramidal cells and congested blood vessels with moderate-high glial cells infiltration ( $\rightarrow$; fig. 9b). Rats treated with oral CBZ group III displayed relatively intact neurons, which appeared with milder glial cells infiltration $(\rightarrow)$ in CA zones and milder edema in dentate gyrus of the hippocampus compared to PTZ injected rats (fig. 9c). In the meantime, brains from the rats treated with intranasal optimized CBZ $\mathrm{F}_{0}$ group IV presented intact neurons $(\rightarrow)$ in CA region, however they showed edema with higher glial cells infiltration in the gyrus region as compared to oral CBZ (fig. 9d). Interestingly in the intranasal CBZ group, there was higher glial cells infiltration. Glial cells play an important role in maintaining and supporting neural cells. Much like fibrocytes in other tissues, glial cells undertake an important part of wound healing following an insult to the brain. Thus, more glial cell infiltration and gliosis suggests that more extensive damage has occurred in this group compared to the oral CBZ. This might indicate more drug uptake by the brain from the intranasal route [38]

\section{CONCLUSION}

In the present work, optimization of carbamazepine (CBZ) nano vesicular structures was achieved using $2^{3}$ multifactorial design. The novel CBZ spanlastic $\left(\mathrm{F}_{0}\right)$ was successfully formulated showing high viscosity that allowed its use in the nasal route without the need of a gelling agent, also improvement of the in vitro release was noticed in addition to its stability for six months of storage at $25{ }^{\circ} \mathrm{C}$ with similarity factor $\left(f_{2}\right)$ of 68 . The optimized spanlastic formulation showed a decrease in latency time in behavior assessment test using elevated plus Maze test. $\mathrm{F}_{0}$ also showed a decrease in serum eNOS and TNF- $\alpha$ and an increase in GSH when compared with the oral CBZ suspension. The histopathological study revealed the more CBZ uptake by the brain. CBZ novel spanlastic vesicles were successfully formulated and examined to be administered via nasal route for brain targeting.

\section{AUTHORS CONTRIBUTIONS}

All the author have contributed equally

\section{CONFLICT OF INTERESTS}

No potential conflicts of interest are reported by the authors

\section{REFERENCES}

1. Karanja SW. Prevalence of emotional and behavioral problems in children with epilepsy attending the child neurology clinic at kenyatta national hospital (Doctoral dissertation, Department of Psychiatry, University of Nairobi); 2017.

2. Durelli L, Massazza U, Cavallo R. Carbamazepine toxicity and poisoning. Med Toxicol Adverse Drug Exp 2012;4:95-107.

3. Ayano G. Bipolar disorders and carbamazepine: pharmacokinetics, pharmacodynamics, therapeutic effects and indications of carbamazepine: review of articles. J Neuropsychopharmacol Ment Heal 2016;1:2.

4. Patel RB, Patel MR, Bhatt KK, Patel BG, Gaikwad RV. Microemulsion-based drug delivery system for transnasal delivery of carbamazepine: preliminary brain-targeting study. Drug Delivery 2016;23:207-13.

5. Faraji AH, Wipf P. Nanoparticles in cellular drug delivery. Bioorg Med Chem 2009;17:2950-62.

6. Bhatia S. Nanoparticles types, classification, characterization, fabrication methods and drug delivery applications. Nat Polym Drug Delivery Syst Cham: Springer International Publishing; 2016. p. 33-93.

7. Marianecci C, Di Marzio L, Rinaldi F, Celia C, Paolino D, Alhaique $\mathrm{F}$, et al. Niosomes from $80 \mathrm{~s}$ to present: the state of the art. Advances in colloid and interface science. 2014;205:187-206.

8. Badawi A, MA Elnabarawi, RTA Elrehem, BA Fayed. Formulation and evaluation of dispersed permethrin proniosomes in powder and microemulsion-based hydrogel bases for the treatment of scabies. Int J Pharm Pharm Sci 2015;8:221-9.

9. Celia C, Cosco D, Paolino D, Fresta M. Nanoparticulate devices for brain drug delivery. Med Res Rev 2011;5:716-56.

10. Bragagni M, Mennini N, Ghelardini C, Mura P. Development and characterization of niosomal formulations of doxorubicin aimed at brain targeting. J Pharm Pharm Sci 2012;15:184-96.

11. Kakkar, Kaur. Spanlastics-a novel nanovesicular carrier system for ocular delivery. Int J Pharm 2011;413:202-10.

12. Kaur IP, Rana C, Singh M, Bhushan S, Singh H, Kakkar S. Development and evaluation of novel surfactant-based elastic vesicular system for ocular delivery of fluconazole. J Ocular Pharmacol Ther 2012;28:484-96.

13. Abdelrahman FE, Elsayed I, Gad MK, Elshafeey AH, Mohamed MI. Response surface optimization, ex vivo and in vivo investigation of nasal spanlastics for bioavailability enhancement and brain targeting of risperidone. Int J Pharm 2017;530:1-1.

14. Chandu VP, Arunachalam A, Jeganath S, Yamini K, Tharangini K, Chaitanya G. Niosomes: a novel drug delivery system. Int J Novel Trends Pharm Sci 2012;2:25-31.

15. Tayel SA, El-Nabarawi MA, Tadros MI, Abd-Elsalam WH. Duodenum-triggered delivery of pravastatin sodium via enteric surface-coated nanovesicular spanlastic dispersions: development, characterization and pharmacokinetic assessments. Int J Pharm 2015;483:77-88.

16. Gaafar PM, Abdallah OY, Farid RM, Abdelkader H. Preparation, characterization and evaluation of novel elastic nano-sized niosomes (ethoniosomes) for ocular delivery of prednisolone. J Liposome Res 2014;24:204-15.

17. Singh A. An overview of the optimization modelling applications. J Hydrol 2012;466:167-82.

18. Al-Mahallawi AM, Khowessah OM, Shoukri RA. Enhanced non invasive trans-tympanic delivery of ciprofloxacin through encapsulation into nano-spanlastic vesicles: fabrication, in vitro characterization, and comparative ex-vivo permeation studies. Int J Pharm 2017;522:157-64.

19. Obay BD, Tassdemir E, Tümer C, Bilgin HM, Atmaca M. Dose dependent effects of ghrelin on pentylenetetrazole-induced oxidative stress in a rat seizure model. Peptides 2008;29:448-55.

20. Zamani Esmati $M$, Malakzadeh $H$, Jenab Esfahani $H$, Eshaghabadi A, Ghasemi S, Jafarian M. The effect of carbamazepine on neuronal damage in pentylentetrazole model of seizure. Neurosci J Shefaye Khatam 2015;3:42-8.

21. Gülen B, Dur A, Serinken M, Karcioglu O, Sonmez E. Pain treatment in patients with acute pancreatitis: a randomized controlled trial. Turk J Gastroenterol 2016;27:192-6.

22. Naidu PS, Singh A, Kulkarni SK. Reversal of reserpine-induced orofacial dyskinesia and cognitive dysfunction by quercetin. Pharmacology 2004;70:59-67.

23. Agarwal NB, Agarwal NK, Mediratta PK, Sharma KK. Effect of lamotrigine, oxcarbazepine and topiramate on cognitive functions and oxidative stress in PTZ-kindled mice. Seizure 2011;20:257-62.

24. Arhan E, Serdaroglu A, Ozturk B, Ozturk HS, Ozcelik A, Kurt N, et al. Effects of epilepsy and antiepileptic drugs on nitric oxide, lipid peroxidation and xanthine oxidase system in children with idiopathic epilepsy. Seizure 2011;20:138-42.

25. O Olaibi OK, Osuntokun OS, Ijomone OM. Effects of chronic administration of gabapentin and carbamazepine on the histomorphology of the hippocampus and striatum. Ann Neurosci 2014;21:57.

26. Araujo J, Gonzalez Mira E, Egea MA, Garcia ML, Souto EB. Optimization and physicochemical characterization of a triamcinolone acetonide-loaded NLC for ocular antiangiogenic applications. Int J Pharm 2010;393:168-76.

27. Bhalaria MK, Naik S, Misra AN. Ethosomes: a novel delivery system for antifungal drugs in the treatment of topical fungal diseases. Indian J Exp Biol 2009;47:368-75.

28. Ruckmani K, Sankar V. Formulation and optimization of zidovudine niosomes. AAPS PharmSciTech 2010;11:1119-27.

29. Kakar R, Rao R, Goswami A, Nanda S, Saroha K. Proniosomes: an emerging vesicular system in drug delivery and cosmetics. Der Pharmacia Lett 2010;2:227-39. 
30. Soliman SM, Abdelmalak NS, El-Gazayerly ON, Abdelaziz N. Novel non-ionic surfactant proniosomes for transdermal delivery of lacidipine: optimization using 23 factorial design and in vivo evaluation in rabbits. Drug Delivery 2016;23:1608-22.

31. A Aboelwafa AA, El-Setouhy DA, Elmeshad AN. Comparative study on the effects of some polyoxyethylene alkyl ether and sorbitan fatty acid ester surfactants on the performance of transdermal carvedilol proniosomal gel using experimental design. AAPS PharmSciTech 2010;11:1591-602.

32. ElMeshad AN, Mohsen AM. Enhanced corneal permeation and antimycotic activity of itraconazole against candida albicans via a novel nanosystem vesicle. Drug Delivery 2016;23:2115-23.

33. Ammar HO, Haider M, Ibrahim M, El Hoffy NM. In vitro and in vivo investigation for optimization of niosomal ability for sustainment and bioavailability enhancement of diltiazem after nasal administration. Drug Delivery 2017;24:414-21.

34. Kamboj S, Saini V, Bala S. Formulation and characterization of drug loaded nonionic surfactant vesicles (niosomes) for oral bioavailability enhancement. Sci World J 2014. http://dx.doi.org/10.1155/2014/959741

35. Basha M, Abd El-Alim SH, Shamma RN, Awad GE. Design and optimization of surfactant-based nanovesicles for ocular delivery of clotrimazole. J Liposome Res 2013;23:203-10.

36. El-Ridy MS, Yehia SA, Mohsen AM, El-Awdan SA, Darwish AB. Preparation, characterization and in vivo evaluation of span 60lornoxicam niosomes. Res J Pharm Biol Chem Sci 2017;8:398411.
37. Shukr MH, Eltablawy NA. Development and optimization of novel controlled-release pioglitazone provesicular powders using $3^{2}$ factorial design. Drug Delivery Translational Res 2015;5:51-62.

38. Al-Mahallawi AM, Khowessah OM, Shoukri RA. Enhanced non invasive trans-tympanic delivery of ciprofloxacin through encapsulation into nano-spanlastic vesicles: fabrication, in vitro characterization, and comparative ex-vivo permeation studies. Int J Pharm 2017;522:157-64.

39. Ahmadirad N, Shojaei A, Javan M, Pourgholami MH, Mirnajafi Zadeh J. Effect of minocycline on pentylenetetrazol-induced chemical kindled seizures in mice. Neurol Sci 2014;35:571-6.

40. Bhardwaj M, Kumar A. Neuroprotective mechanism of coenzyme Q10 (CoQ10) against PTZ induced kindling and associated cognitive dysfunction: possible role of microglia inhibition. Pharmacol Reports 2016;68:1301-11.

41. Gomez CD, Buijs RM, Sitges M. The anti-seizure drugs vinpocetine and carbamazepine, but not valproic acid, reduce inflammatory IL- $1 \beta$ and TNF- $\alpha$ expression in rat hippocampus. J Neurochem 2014;130:770-9.

42. Lee Y, Shin T. Expression of constitutive endothelial and inducible nitric oxide synthase in the sciatic nerve of lewis rats with experimental autoimmune neuritis. J Neuroimmunol 2002;126:78-85.

43. Kaneko K, Itoh K, Berliner LJ, Miyasaka K, Fujii H. Consequences of nitric oxide generation in epileptic-seizure rodent models as studied by in vivo EPR. Magnetic Resonance Med: Official J Int Soc Magnetic Resonance Med 2002;48:1051-6. 